\title{
Consequences of poverty on economic decision-making: Assessing the verisimilitude of the cognitive mechanism
}

\author{
Matúš Adamkovič \\ Institute of Psychology, Faculty of Arts, University of Prešov, Prešov, Slovakia \\ Correspondence: matho.adamkovic@gmail.com
}

\begin{abstract}
The paper aims to assess the verisimilitude of the hypothesized model of poverty perpetuation linking socioeconomic situation and economic preferences via cognitive load, executive functions, and intuitive/deliberative decision-making style. The proposed model as a whole has not found required support in data, and simultaneously, the dyadic relationships between the variables have been mainly weak. Sensitivity analysis has revealed that the majority of the observed estimates varies substantively depending on the arbitrary analytic decisions of the researcher. The findings could be primarily attributed to (1) the possibility that the nature of economic preferences resembles stable personality traits and hence the preferences are only weakly determined by cognitive dispositions or patterns of emotional/cognitive responses in a long run; (2) the high social equality and relatively low poverty rate in Slovakia, which currently allows the majority of the inhabitants to afford elementary goods and meet the basic needs, regardless of their economic situation; (3) the fact that the current state of knowledge in behavioral sciences is burdened by multiple problems (e.g., lack of good theory, complicated issue of causality, prevalence of questionable research practices, or publication bias), resulting into poor replicability and low credibility of the knowledge, implies that the theories upon which the model was built might not necessarily be true. The hypothesized cognitive mechanism does not allow to explain what economic decision-making depends on, neither why do people fall into poverty traps.
\end{abstract}

\section{Key words}

Economic situation; poverty; cognitive mechanism; economic decision-making; poverty perpetuation

\section{Introduction}

People living in poverty are said to have suboptimal economic preferences that could play an important part in poverty perpetuation (Kraay \& McKenzie, 2014). Specifically, their willingness to delay gratification should be lowered (see, for example, Brown, Ivković, \& Weisbenner, 2015; Griskevicius, Tybur, Delton, \& Robertson, 2011) and they should be more reluctant to risk when a reward is involved (Haushofer \& Fehr, 2014). Although there exists a substantial body of literature focused on the correlates of poverty (for its review see Pepper $\&$ Nettle, 2017), up until recently, no formal model dedicated to grasp poverty perpetuation from a perspective of an individual has been created. Recently, Adamkovič and Martončik (2017) 
proposed a theoretical model explaining how poverty influences one's economic decisionmaking. The model has been linking socioeconomic status and economic preferences via cognitive load, executive functions, and intuitive/deliberative style of decision-making. The authors provide a narrative review and a psychological rationale of the causal mechanism they have hypothesized. The model, however, has not yet been tested against data. In this paper, we first provide an additional theoretical background to the model, then we test the model against 3 datasets and, consequently, discuss the findings.

\section{The model and its caveats}

In short, the model by Adamkovič and Martončik (2017) depicts that poverty creates cognitive load in the form of experiencing negative affect and stress. The cognitive load, not poverty per se, impairs one's executive functions, namely, attention focus, working memory and selfcontrol capacity. The executive functions are mutually related but only self-control capacity has a direct effect on a person`s intuitive/deliberative style of thinking. Both one`s self-control and intuitive/deliberative style of thinking causally affect economic decision-making. In the presented model, economic decision-making is represented by time-discounting and risk preference when reward/loss is involved. The economic preferences are also determined by one`s financial literacy.

The initially proposed model has several caveats that should be addressed. Some of them have already been taken into account in the initial model/paper but we believe they need more explicit clarifications. (1) Taken from the beginning of the causal mechanism, it disregards the fact that poverty is a multidimensional construct (Smeeding, 2015) and its subjective assessment likely plays a more important role in the executive processes than its objective indicators (Mani, Mullainathan, Shafir, \& Zhao, 2013). (2) Second, even though we use the term poverty, we refer to the whole range of economic status. Focusing only on the people who are considered poor (whatever the operationalization is used) will lead to an unwanted phenomenon called range restriction (see Pedhazur \& Pedhazur Schmelkin, 1991). Restricting the sample to the poor will lead to loss of information (e.g., if the model holds true, we could easily fool ourselves by claiming that the result is unique for the poor even though the process could be same for the whole spectrum of economic situation) and likely attenuated effect sizes. (3) The fundamental notion upon which the model has been built - that poverty leads to suboptimal economic trade-offs, does not, in fact, have as strong support in the evidence as the narrative often presents. For instance, in a large cross-national study by Falk, Becker, Dohmen, Enke, Huffman, \& Sunde (2015), after controlling for covariates, the relationship between household income and time-discounting and risk-taking is very weak with $\beta=0.04$ and $\beta=$ 0.06 , respectively. A similarly weak associations can be found throughout the relevant literature (for an overview see Adamkovič, Martončik, \& Ropovik, 2018), perhaps with the exception of the study by Brown et al. (2015), who found that people with liquidity constraints are about $20 \%$ more likely to choose a more present-oriented option. (4) Another potential pitfall of the model is the issue of modeling causality from cross-sectional data in behavioral sciences (see, for example, Pearl, 2009; Rohrer, 2018). Although the authors claim the model describes a potential cognitive mechanism of poverty perpetuation, it is acyclic (as a cyclic model of this 
complexity will not meet the assumptions of order condition and rank condition; Kline, 2016) and the feedback loop from economic decision-making to poverty causing the poverty trap is assumed only theoretically. Additional potential causality-related problem is that conditioning on colliders or mediators leads to biased estimates (Greenland, 2003; Pearl, 2009). The model, however, implicitly deals with these issues and only a slight modification (described in "The current version of the model section) has been made in order to have the causality of the paths in the model as much theoretically justifiable as possible. (5) Aside from these points, omittedvariable bias can be regarded as another potential issue. One could argue that the model is missing some key elements like, for example, intelligence, perceived reliability of the environment, motivational factors, macroeconomic and political expectations or sociodemographic variables (e.g., gender, time spent living in poverty, social unit, etc.). This might be indeed true, yet any statistical model is a simplification of real-world processes and, in fact, cannot comprises all the possible variables. Having and testing alternative models (or the similar model but employing different choices throughout the process - see researcher degrees of freedom; Simmons, Nelson, \& Simonsohn, 2011; Wicherts, Veldkamp, Augustejin, Bakker, van Aert, \& van Assen, 2016) is a subject of constructive and conceptual replications. (6) Exhaustion of one's mental resources is a core assumption of the model. Usually, this notion is associated with the infamous ego-depletion theory that has been falsified in the vast majority of the replication studies. This might imply that the proposed model could not hold true. The fact is that although the concept of ego-depletion is popular, it is not the only theory depicting how (the lack of) self-control determines one`s decision-making. For instance, there exist other two competing models of self-control, specifically, the Process model (Inzlicht \& Schmeichel, 2012) and the CoMo model (Dang, 2018). Especially the CoMo model can explain the motivational shifts that lead an individual to more hedonistic, in this case more myopic, choices.

\section{The current version of the model}

In order to verify the verisimilitude of the proposed cognitive mechanism of poverty perpetuation, we aimed to model the variables and their relationships as close to the initial model as was possible. Slight modifications, however, have been made. Namely, we have dissected the latent variable representing poverty into two components - objective economic situation and subjective economic situation. Objective economic situation has a direct effect on its subjective perception but does not causally affect any other variable in the model. In other words, subjective perception of own economic situation blocks the causal flow from objective economic situation to experiencing negative affect and stress (i.e., from a perspective of objective economic indicators, a person can be considered poor but it is her perception of the situation, not the wealth itself, that affects her levels of negative affect and distress). For the practical reasons associated with data collection, we have had to omit the variable representing one's attention from the model. Furthermore, given the current evidence that shows negligible relationships between working memory and self-control (Nęcka, Gruszka, Orzechowski, Nowak, \& Wójcik, 2018; Singh \& Göritz, 2018), we have refrained from the initial assumption of a causal path between the two. The conceptual visualization of the current version of the model is depicted in Figure 1. Testing the model against data will reveal whether this narrativebased cognitive mechanism can indeed explain the process of poverty perpetuation. 


\section{Methods}

\section{General information}

The aim of the paper is to verify whether the hypothesized model depicting how poverty influences one's economic decision-making via cognitive load, executive functions, and intuitive/deliberative style of thinking holds true when confronted with data and to examine the magnitude of the relationships between the variables in the model. To do so, we conducted 3 studies - exploratory, confirmatory, and replication. In the case the tested model is falsified in the exploratory dataset, the only acceptable modifications will be those that are theoretically justifiable and, at the same time, will still fit the original theoretical framework of the proposed mechanism. The modified model will be then cross-validated on the confirmatory dataset. The third dataset will be used for a constructive/conceptual replication (see Hüffmeier, Mazei, \& Schultze, 2016) of the findings.

Initially, two sets of data $\left(\mathrm{N}_{1}=430, \mathrm{~N}_{2}=500\right)$ were collected to answer the research question. Due to the financial constraints, the participants were incentivized only in the form of a small non-financial reward (see Participants section). Taking into account the feedback from referees (reviewing other related papers) who wished to see how the results would change if participants get incentivized with real money, we have added a third research sample $\left(\mathrm{N}_{3}=252\right)$ into the analyses. However, the data for the third wave of data collection comes from a hitherto unpublished experiment (see the preregistration at: https://osf.io/z3jyf) and might be biased because of the experimental situation (note that the experimental conditions had had nil effect on the outcome variable - time-discounting and was administered only after the rest of the test battery had been completed). We, therefore, report these results as a piece of additional evidence and the specific estimates should be interpreted with particular caution. We also consider this study not as a close replication but rather as an attempt of a constructive/conceptual replication of our findings, since some of the measures slightly differ and it does not include negative affect and risk preference variables.

Participants, data collection, data screening, and power analysis

Data were collected in 3 waves: (1) $\mathrm{N}_{1}=430$ (218 women), Age $1=40.05 \pm 11.88$ years; (2) $\mathrm{N}_{2}=500$ ( 250 women), Age $2=39.57 \pm 11.48$ years; (3) $\mathrm{N}_{3}=252$ (204 women), Age $_{3}=34.92$ \pm 10.31 years. The data from the first two samples were collected online via a local agency specializing in data collection and market research. The agency works on principles similar to MTurk. In these cases, the participants were rewarded by credits that they could spend on a variety of the products offered by the agency. In the third data collection, participants were recruited in person and the materials were administered via the paper-pencil form. This time, the participants were incentivized by a real monetary reward ranging from 6-12 euros, depending on their intertemporal preference. All the data collections had ethical clearance granted by the ethics board of the Institute of Psychology, University of Presov. All the data were collected as a part of bigger data collections for the research project "Psychological causes and consequences of poverty" (grant no. APVV-1504-04). 
In the time of data collection, $63 \%$ of the total number of participants were employed or selfemployed, $11 \%$ were unemployed, $7 \%$ considered themselves primarily as full-time students, $10 \%$ were retired or been receiving other forms of pension, and the remaining $9 \%$ found the option "other" as the most suitable. $2 \%$ of them had achieved a maximum of primary education, $60 \%$ had finished their secondary education, and the remaining $38 \%$ had successfully pursued an academic degree.

We screened the datasets for careless responders. In the online data collections, we examined the longstrings (see Curran, 2016; we considered the participants with the length of the longstrings $>2.5 \mathrm{SD}$ as potentially careless) and their answers to open-ended questions. In the case of the offline recruitment, we also screened the longstrings (based on the same rule as in the previous cases) and checked whether or not they passed attention checks (if a participant failed more than 1 out of 3 attention checks, we considered her as careless). A total sample consisting of 1143 participants $\left(\mathrm{N}_{1}=418, \mathrm{~N}_{2}=485, \mathrm{~N}_{3}=240\right)$ has remained after excluding the seemingly careless respondents.

All the sample sizes were determined by the financial capabilities. RMSEA-based power analysis $(\alpha=.05$; Ha RMSEA $=.08$; H0 RMSEA $=.04 ; \mathrm{df}>200$ given the approximate smallest number of the estimated relationships in the model) yielded more than $99 \%$ power to indicate that the whole structural model is misspecified. Even the research design with the smallest number of participants $\left(\mathrm{N}_{3}=240\right)$ showed almost $90 \%$ power (given the conventional $\alpha=.05$ for the two-sided test) to be able to detect our smallest effect size of interest, $r=.2$, for the estimated relationships.

\section{Measures}

The participants were administered a test battery composed of several measures. Here, we provide only a brief summary of the measures, including their reliabilities estimated on our samples. For a more detailed overview of the employed measures please see https://osf.io/z6sej/. Descriptive statistics of the measures can be found in Table 1.

Objective poverty (objective economic situation) was measured as equivalized household income (Hagenaars, de Vos, and Asghar Zaidi, 1994). Subjective poverty (subjective perception of own economic situation) was reflected by 3 indicators, namely, The MacArthur scale of subjective social status (Adler \& Stewart, 2007; Giatti, Camelo, Rodrigues, \& Baretto, 2012), the mean score of the created 6-item scale of financial satisfaction $(\omega=.92-.93) ; 1$-item perception of own poverty/wealth. The exception was made in Study 3 where only 3 items of the financial satisfaction scale were administered $(\omega=.92)$. Negative affect was assessed by PANAS (Watson, Clark, \& Tellegen, 1988; $\omega=.92$ ), the level of perceived stress was measured by the Perceived stress scale (Cohen, Kamarck, \& Mermelstein, 1983, $\omega=.81-.86$ ). A digit span test was used to measure working-memory $(\omega=.81-.86)$. To measure participants` selfcontrol, the Self-control scale (Tangney, Baumeister, \& Boone, 2004, $\omega=.75-.81$ ) was used. In order to examine the tendency of intuitive/deliberative thinking, a test of cognitive reflection containing 3 items from the original Cognitive reflection test (Frederick, 2005) and 3 additional 
items proposed by (Oldrati, Patricelli, Colombo, \& Antonietti, 2016) was used ( $\omega=.80-.87$ ). To assess participants' economic preferences, we employed the Staircase time and risk modules, as proposed by Falk, Becker, Dohmen, Huffman, and Sunde (2016). In the case when risk preference involved a loss, we adopted the Staircase module and reduced the amount of money to half. In Study 2, we also administered IMCQ (Kirby, Petry, \& Bickel, 1999; Kaplan, Amlung, Reed, Jarmolowicz, McKerchar, \& Lemley, 2016) as an additional measure of timediscounting. In Study 3, time-discounting was assessed as the participant preference between 6 euros now, 8 euros in 10 days, 10 euros in 20 days, and 12 euros in a month. To measure financial literacy, we used 6/8 items proposed by Lusardi $(2008 ; \omega=.70-.81)$.

-- Table 1 about here --

Statistical analysis

First, we screened all datasets for careless responses (see Participants section) and improbable values. Then we both statistically and visually checked the descriptive statistics. We assumed no responses as outliers as we believe these data points represent the true distribution of the construct in the population. The data were not transformed except for dividing equivalized household income by 100 to reduce its variance and to allow for easier convergence when estimating the models. No missing data were present in the two online data collections. In Study 3 , approximately $8 \%$ of the data were missing and have been imputed using mice package (van Buuren \& Groothuis-Oudshoorn, 2011).

We used the data from Study 1 to examine the factor structures of the measured constructs (measurement models). Items with the factor loadings $<.40$ had been omitted from the further analyses (see Stevens, 1996). Other items had been excluded based on a combination of high cross-loadings, residuals, and modification indices. We then created parcels from the remaining items, simply to reduce the number of indicators (note: we have also applied other approaches to estimate the measurement models, for more details see Sensitivity analysis section). We also used this dataset to examine and address any other misspecifications of the hypothesized model, however, only in the case the modifications were theoretically justifiable and did not substantially diverge from the proposed mechanism. The original model, as well as the respecified ones, were then (dis)confirmed on the data from Study 2. Study 3 served to see how the results replicate under the slightly different circumstances (i.e., the method of data collection, slightly different measures, omitted variables of negative affect and risk preferences, addition of a real monetary reward).

The structural models were estimated in R package lavaan (Rosseel, 2012). The models were estimated using WLSMV (means- and variance-adjusted weighted least squares) with all the variables (except for the equivalized household income) being modelled as ordinal. The models were regarded as falsified based on their chi-square value (a significant chi-square test statistic indicates a misfit of the model) as it is the only formal omnibus test of the (mis)fit of the whole model (Ropovik, 2015). In the exploratory part, we have aimed to adapt the model in order to achieve a non-significant chi-square, but only as far as the modifications were theoretically 
justifiable and in accordance with the main idea behind the proposed mechanism. We also diagnosed the fit of each model employing the scaled conventional approximate fit indices (AFI), namely, CFI, TLI, RMSEA, and SRMR.

In addition to the frequentist approach of estimating the paths, we also assessed the degree of comparative evidence calculating the approximate Bayes Factors (BF). BFs represent the relative evidence of the data supporting alternative hypothesis (the parameter is freely estimated) over the null (the parameter fixed to 0 ). Furthermore, we estimated the posterior probability - the probability of the observed estimates being non-zero, assuming the equal prior odds $(1: 1)$ of $\mathrm{H}_{0}$ and $\mathrm{H}_{\mathrm{a}}$ being true.

Code and data are available at: https://osf.io/qy8mn/.

Sensitivity analysis

As the results might be a subject to different analytical decisions when analyzing the data, we decided to inspect their robustness. Particularly, as the measurement models of psychological variables could be often unstable, we focused to examine how different approaches to the construction of measurement models shape the obtained estimates. We have, therefore, computed the same structural model multiple times using the different types of measurement models, such as: 1) item parcelling; 2) using the exploratory CFA-based items; 3) using all items; and 4) using only the items that best represent the latent construct (see Hayduk \& Littvay, 2012), taking into account a combination of their statistical parameters and subjective assessment of their content validity. This sort of sensitivity analysis does not cover all the possible choices made by the researchers, however, in this case, it addresses the majority of the arbitrary analytic choices that could have had a substantial impact on the results. A brief summary of the sensitivity analysis is presented in the results and interpreted in the discussion.

\section{Results}

\section{Study 1 - exploratory testing of the model}

Before testing the actual model against the data, we examined the factor structures of the measures via CFA. The measurement models were then modified based on the criteria described above. We had omitted 3 items (no. 3, 5, and 7) from the PANAS, 4 items (no. 1, 4, 5 , and 7) from the PSS, first 3 items from the digit span test, and 5 items (no. 1, 2, 6, 8, and 12) from the Self-control scale. The Cognitive reflection test, as well as the financial literacy scale, remained intact. These modifications of the measurement models have led to a substantial increase in their fit (see https://osf.io/r97mt/). Despite these changes, the significant chi-square statistics of the modified PANAS, PSS, and Self-control scale still indicated a misspecification of the factors. In order to preserve the content validity of the scales, we did not make any further modifications/exclusions to forcefully obtain a non-significant chi-square value. The results we report primarily were obtained from the measurement models formed by parceling the remaining items. 
The obtained estimates indicate the hypothesized model (for its conceptual visualization see Figure 1) substantially deviates from the observed data $\left(\chi^{2}(78)=839.76, p<.001 ; \mathrm{CFI}=.76\right.$; $\mathrm{TLI}=.82 ; \mathrm{RMSEA}=.15,95 \% \mathrm{CI}[.15, .16] ; \mathrm{SRMR}=.11)$. After a thorough inspection of the residual matrix, modification indices, and zero-order bivariate correlations, we decided the only theoretically justifiable adjustment of the model was to add a covariance term between negative affect and stress. This has led to a decrease in the chi-square statistic to a half of its original value, nonetheless, it still indicated a misspecification of the model $\left(\chi^{2}(80)=422.02, p<.001\right)$. We then again examined the potential reasons of the observed misfit. The modification indices suggested to add a covariance between cognitive reflection and financial literacy or a reversed causality between economic preferences and financial literacy (in a way that economic preferences determine one's financial literacy). The other observed misspecifications were either negligible from a statistical perspective or only hardly justifiable. In an exploratory manner, due to the problem with financial literacy, we decided to exclude it from the model. Having financial literacy excluded, the approximate fit indices showed values that are consensually considered as very good $-\mathrm{CFI}=.97$; TLI $=.98$; RMSEA $=.06,95 \%$ CI $[.05, .09]$; $\mathrm{SRMR}=.05$. The omnibus chi-square test, however, has still indicated a model`s misfit $\left(\chi^{2}(74)\right.$ $=188.78, \mathrm{p}<.001)$. No further modifications have been made as we had no appropriate theory to support them.

\section{Study 2 - confirmatory testing of the model}

Since the measures of working memory and financial literacy differed from Study 1, we computed CFAs. Similarly to the exploratory testing, we had excluded the first 3 (easiest) items of the digit span test. We had excluded one newly added item from the financial literacy scale because it did not load on the latent factor at all. The modified scales have yielded seemingly very good AFI, but the chi-square test revealed beyond-chance deviations from the data (please note that the results of CFAs for all 3 studies are available at: https://osf.io/r97mt/).

Testing the proposed model against the data from Study 2 has shown very similar results relative to those from Study $1\left(\chi^{2}(83)=1024.33, \mathrm{p}<.001 ; \mathrm{CFI}=.77\right.$; TLI $=.81$; RMSEA $=$ $.15,95 \%$ CI $[.15, .16]$; SRMR $=.11)$. In respect to the exploratory testing, we had allowed a covariance between negative affect and financial literacy. This has again led to an increase in model fit, particularly reducing the chi-square value to a half $\left(\chi^{2}(83)=546.62, p<.001\right)$ however, the model can still be considered falsified. Taking into account the issues with financial literacy observed in the previous data analysis, we had additionally excluded the variable from the model to see whether the results replicate or not. The fit parameters of the model without financial literacy have been very alike to the estimates observed in Study 1, with the maximum difference between AFIs equal to \pm .03 .

\section{Study 3 - conceptual replication}

All the measures used in Study 3, apart from the shortened version of the financial satisfaction scale, were already administered in the previous studies and hence we worked with their modified forms that are already described above. The whole model has shown a rather poor fit 
$\left(\chi^{2}(67.20)=213.52, \mathrm{p}<.001 ; \mathrm{CFI}=.76 ; \mathrm{TLI}=.78 ; \mathrm{RMSEA}=.10,95 \%\right.$ CI $[.09, .11] ; \mathrm{SRMR}$ $=.10)$. Since Study 3 did not include negative affect measure, the only potential modification corresponding with the previous findings, was to remove financial literacy. The exclusion of financial literacy had actually led to a slightly better fit $\left(\Delta \chi^{2}(12.34)=41.63, p<.001\right)$. After a closer inspection of the causes of the model's misfit, we found that excluding cognitive reflection from the model is the main modification that substantially improves its parameters. Since this potential adjustment goes against the theoretical framework of the model, we did not investigate this possibility and neither we report it any further. This replication, too, has shown the proposed model does not fit the data, even using real financial incentives. For the summary of chi-square statistics and AFIs of all the estimated structural models see Table 2.

-- Table 2 about here --

\section{Regression estimates and their stability}

Over 50 regression coefficients have been estimated from the primarily reported analysis and thus will not be interpreted and discussed separately. The exact values of the coefficients for the model with the covariance between negative affect and stress (applies for Study 1 and 2) can be found in Table 3. Other regression estimates are available within the sensitivity analysis document: https://osf.io/r97mt/.

In general, the following can be inferred: (1) 13 out of 18 standardized regression coefficients (between Study 1 and 2), and 9 out of 18 coefficients (between all studies) have been successfully cross-validated with the biggest difference equal to \pm .1 , which suggests relatively high stability across the datasets. (2) The markedly biggest differences in regression coefficients between the datasets have been observed in the cases of the effect of working memory on cognitive reflection control $(\Delta \beta=.48)$ and the effect of stress on self-control $(\Delta \beta=.46)$. (3) The specific regression coefficients have been small in general and only 3 paths had $\mathrm{BF}_{10}$ greater than 3 in all studies, suggesting more than just anecdotal evidence in favor of alternative hypothesis (Jeffreys, 1961; Lee \& Wagenmakers, 2013). (4) We have found that the hypothesized predictors of economic preferences have, in fact, null effects, when a hypothetical reward is involved. In the case of real monetary reward, financial literacy has a substantive effect on one`s preference $(\beta=.34)$. (5) After the exclusion of financial literacy in Study 1 and 2 , the majority of regression parameters had changed only negligibly (the differences were in hundredths). The only markedly bigger changes were observed in BFs of the estimates between cognitive reflection and time-discounting measures $(\mathrm{BF} 10=0.06$ and $0.31 \rightarrow \mathrm{BF} 10=1.24$ and 4.90 ; and $\mathrm{BF} 10=0.21 \rightarrow \mathrm{BF} 10=2.45$ for the second measure, respectively). Given the fact that each model has been falsified, some of the regression estimates might be biased and need to be interpreted with caution.

-- Table 3 about here --

\section{Summary of the sensitivity analysis}


Different methods of defining the measurement models (i.e., modelling all the items that had remained after CFA; modelling all the items; modelling the best items) have yielded very similar results to those obtained by parceling in terms of model fit and the needs for respecification. No matter how we constructed the measurement models in Study 1 and 2, the only identified substantial modification of the structural model was to add a covariance between negative affect and stress. Again, after this modification, the presence of financial literacy in the model appeared to be the most crucial issue. The stability of the regression coefficients, however, has varied depending on the specific measurement model with the biggest deviations being caused by selecting the best items. The most stable coefficients have been found between economic preferences and their predictors - the range of the differences between (point) regression estimates has varied between $\Delta \beta=-.29-.29$. On the contrary, the least stable regression coefficients have been found between self-control and negative affect, and selfcontrol and stress with $\Delta \beta \approx 1.2$ as the difference between the smallest and the greatest value. The conducted sensitivity analysis confirms that whereas the model is being constantly falsified regardless the measurement model, the observed relationships are rather unstable and should be (perhaps with the exception of the relationships between the aspects of economic decisionmaking and its predictors) interpreted with particular caution.

\section{Discussion}

The aim of the paper was to assess the verisimilitude of the hypothesized model of poverty perpetuation by testing the model against the data from 3 independent studies. The results indicate that the proposed model has not found necessary support in the data. Furthermore, the specific regression estimates might be biased and as revealed by the sensitivity analysis, they depend on the selected measurement model to a great extent.

The complexity of the model allows to discuss many points. For these partial interpretations of the results please see a dissertation by Adamkovič (2019). In this paper, we wish to provide a meta insight on the factors that are likely to be the causes of the negative results (i.e., the fact that the proposed model has been falsified as well as the fact that the regression coefficients indicate mostly weak relationships between the levels of the model). Despite the existing assumptions that worse economic situation leads to less rational economic decision-making (e.g., Brown et al., 2015; Griskevicius et al., 2011; Pepper \& Nettle, 2017), the data have indicated that the binary relationship between economic situation and economic preferences is weak (point estimates for objective economic situation: $r=-.08-.22$; point estimates for subjective perception of economic situation: $r=-.13-.26$ ) and have no substantial significance. In reality, the observed estimates are very similar to the existing empirical evidence (for its summary see Adamkovič et al., 2018). This implies that the narrative suggesting that people suffering from poverty have less rational economic behavior, for example, are unwilling to delay gratification (Spears, 2011), is not based on ample evidence.

Likewise, many of the other relationships in the model were of much lower magnitude than had been expected. For instance, one could expect that cognitive load deteriorates working memory. A meta-analysis on this topic (Shields, Shazma, \& Yonelinas, 2017) reveals very small effects 
of stress on working memory which will likely get even smaller after a regression-based correction for publication bias is performed (Carter, Schönbrodt, Gervais, \& Hilgard, 2018). The effect of financial literacy on economic preferences can serve as another example. Both according to studies (e.g., Gathergood, 2012; Grohmann, 2018; Lusardi, Michaud, \& Mitchell, 2017) and also naturally, one could expect that financial literacy determines economic preferences. Counterintuitively, a meta-analysis by Fernandes, Lynch, and Netemeyer (2014) suggests that an increase in financial literacy explains less than $1 \%$ of the variance in economic decision-making. Furthermore, after controlling for variables such as one`s willingness to take risks or tendency to plan, financial literacy ceases to be a significant predictor of economic preferences. In this case, it seems that factors determining economic preferences go beyond the construct of financial literacy and could be of a more general nature, for example, perception of time (Zimbardo, Clements, \& Rego Leite, 2017) or level of education (H. Kim, Choi, Kim, $\&$ Pop-Eleches, 2018). These two examples indicate that some of the hypothesized relationships just might have been based on weak or perhaps even incorrect assumptions. As further discussed in the limits of the study, constructing a complex theory by synthesizing the existing evidence could be a tricky task, especially given the replicability issues that behavioral sciences have to face.

The hypothesized cognitive mechanism does not hold true as a whole, shows mostly weak relationships between the variables, and indicate that the facets of economic decision-making are virtually unrelated to any other variables. Thus, a question arises - what variable or variables do determine one's economic preferences? An explanation might dwell in a shift of the perspective. What if economic preferences are stable autonomous (personality) traits (Frey Pedroni, Mata, Rieskamp, \& Hertwig, 2017; Meier \& Sprenger, 2015; Odum, 2011; Pedroni, Frey, Bruhin, Dutilh, Hertwig, \& Rieskamp, 2017) and are substantively determined mostly by very urgent needs or situations of financial (Bickel, Wilson Chen, Koffarnus, \& Franck, 2016) or emotional (Schildberg-Hörisch, 2018) nature and not by one's abilities or knowledge? To test this assumption, we calculated the stability of the specific economic preferences in time on a sample of 224 participants who completed the test battery twice. The results have revealed moderately strong correlations (Pearson's $r$ ) of the preferences in time (time difference between the data collections was approximately 1 year), namely: time-discounting $=.41,95 \%$ CI [.28, $.52]$; risk-reward $=.42,95 \%$ CI $[.29, .53]$; and risk-loss $=.44,95 \%$ CI $[.29, .56]$. The trait-like approach to economic preferences might, however, appear to have its flaws. For example, the other authors studying time stability of this sort of preferences (Chuang \& Schechter, 2015; Odum, 2011; Schildberg-Hörisch, 2018) report various stability for different time intervals. In general, the evidence shows a predictable pattern - the shorter the time interval between the measures, the higher the correlation.

A wealth of literature is dedicated to studying the problems related to psychological measurement. Even though we had employed some of the most cited measures, they could have contributed to the negative results. The content of some items might be considered sensitive or even uncomfortable to answer (e.g., "I am lazy"). It is thus possible that at least some of the responses are subject to social desirability (see Tourangeau \& Yan, 2007). To give an example, imagine a person with lowered self-control. In practice, this implies that people with lower self- 
control could provide answers that are very close to social norms, however, when they have to make an actual decision in term of economic preference, their choice is impulsive. Such reasoning has it flaws, as it is applicable to any part of the administered test battery and it is, in principle, impossible to predict how will social desirability affect the results, if at all. Even though we had not directly controlled for social desirability, we believe that employing a method for detection and subsequent exclusion of careless participants could have also alleviated this issue and contributed towards having more valid results.

Besides the psychological interpretations, the results could be determined by the core sociodemographic characteristics of the research samples. The recent OECD reports (OECD $2018 \mathrm{a} ; 2018 \mathrm{~b})$ shows that Slovakia has the lowest inequality $($ GINI coefficient $=.24)$ and one of the lowest poverty rates $(8.5 \%)$ out of the surveyed countries. These circumstances could allow people to make their ends meet. Once their basic material needs are saturated, the economic decisions could be indeed determined by one's preferences in general, and, therefore, irrelevant of objective financial situation, financial literacy or the whole cognitive mechanism. This would provide even more support for the argumentation that intrinsic economic preferences are to a great extent autonomous behavioral patterns similar to a common comprehension of personality traits.

If we cannot explain poverty perpetuation by this mechanism, can we at least identify the prototype of a person whose economic preferences are more myopic? In an exploratory manner, beyond the main scope of the study, we had aimed to calculate latent class analysis in order to answer this question. Despite the number of extracted classes (2-6), we had not been able to find any meaningful categorization. In other words, people within the classes have been so distinct that we were not able to come out with a theoretically justifiable, and even less predictable, pattern of their characteristics. If poverty perpetuation indeed depends on one`s economic decision-making rather than general (e.g., level of education) or external (e.g., "inherited" economic status) factors, it is needed to explain and empirically examine the parts of this process. It is, however, unknown what alternative mechanism (see, for example, instance-based learning theory; Gonzalez, 2013; Gonzalez, Lerch, \& Lebiere, 2003), and if any, can appropriately explain or help to predict the relationship between economic situation and economic preferences.

\section{Limits of the model and the studies}

The attempt to assess the verisimilitude of such complex model faces several potential pitfalls. (1) As discussed in the beginning of the paper, the first issue is related to researcher degrees of freedom. Selecting the most appropriate variables and forming them into a unitary model while taking into account the most plausible flow of causality between the variables is not really straightforward and can have several alternatives. At the same time, psychological phenomena are often so complex and complicated that a researcher has to compromise between capturing all the potentially relevant variables and parsimony of the model. Thus, testing this exact model is not the only option to capture poverty perpetuation on the level of an individual and future research on the topic could try to cover it very differently. (2) Studying economic preferences 
on hypothetical rewards can be regarded as another limit. The existing empirical evidence that examines whether decision-making involving hypothetical rewards is equivalent to decisionmaking with real financial incentives (for its summary see Xu, Pan, Wang, Spaeth, Qu, \& Rao, 2016) brings ambiguous results. Even after incentivizing participants with real monetary rewards, our data suggest that the model does not hold true and the binary relationships between indicators of economic status and this economic preference are still weak. One of the directions for the future research could dwell in the employment of more realistic scenarios (e.g., specific consumer behavior, taking and managing loans, or gambling) as the indicators of economic decision-making. The preference does not necessarily equal the actual decision. For instance, a person facing material hardship could indeed express a genuine willingness to delay the gratification, however, in a situation with a financial reward (given the equivalent amount of money), it might be much easier to succumb to the vision of having the money "here and now". Conducting a study with a sufficiently powered design where all participants are incentivized with relatively high payments (that are similar to the hypothesized scenarios) is, unfortunately, very problematic in the current situation in behavioral research. The increase in incentives will be associated with the magnitude effect (people are more willing to delay gratification as the value of the reward increases; see Ballard, Kim, Liatsis, Cohen, \& McClure; 2017), potentially leading to different outcomes. (3) At a first glance, analyzing only observational data might appear to be an issue that could have contributed towards the disconfirmation of the model. However, we believe that such complex problem could not be tackled by an experimental approach and hence analyzing the data obtained by self-reported measures (as is a standard in psychology) is just a more appropriate way to answer the given research question, even after admitting its caveats. (4) The falsification of the model can be also attributed to the problems of systemic nature, such as publication bias (e.g., Fanelli, 2012) or lack of a good theory (e.g., Muthukrishna \& Henrich, 2019) in behavioral sciences. That is, at least some of the theories upon which the model has been built might be flawed and hence, integrating these non-valid assumptions into one holistic model should bring negative results by definition. The currently pronounced replicability crisis (for example, Camerer et al., 2018; Open Science Collaboration, 2015) has already been leading to substantial improvements in practices and psychology`s renaissance (Nelson, Simmons, \& Simonsohn, 2018). We, therefore, invite independent researchers to conduct replications on different (non-WEIRD) samples and under different settings (e.g., incentives, measures, etc.), even with modified versions of the hypothesized model.

\section{Conclusion}

Haushofer and Fehr (2014) emphasized the need to study factors potentially contributing to poverty perpetuation. Adamkovič and Martončik (2017) have proposed a theoretical model of a cognitive mechanism describing how poverty affect one`s economic preferences via a cognitive mechanism. Based on the data from 3 studies, we conclude that the model has been falsified, and therefore, the hypothesized mechanism does not explain why a person traps herself in the poverty cycle. Furthermore, even the bivariate relationships between the variables are much smaller than had been expected. The conducted sensitivity analysis has revealed that the majority of the obtained estimates is stable across the datasets, but varies substantively due 
to arbitrary decisions related to the conceptualization of measurement models. We identify 3 main reasons the model did not hold true: 1) Economic preferences have characteristics of stable traits and thus are only weakly determined by one's cognitive abilities or mental load, and instead, they could be subjected to urgent needs. 2) The relatively high level of social equality and the relatively low poverty rate in Slovakia imply that the majority of its inhabitants can afford most necessary commodities and saturate their essential needs regardless of their actual economic situation. Therefore, economic preferences might be independent of financial situation. 3) The body of knowledge in behavioral sciences suffers from several problems (for instance, lack of good theory, ambiguous and vague conceptualizations of constructs, complicated issue of causality, questionable research practices, publication bias), leading to low replicability and hence credibility of our findings. This indicates that the theories used to conceive the model might not hold true after a more thorough examination and thus the model is flawed by definition. Even though the discussion and conclusions presented in this paper comes from 3 different studies, we would like to highlight the need for further replication under different conditions and with enhanced models. For knowledge to be credible, robust evidence is needed.

\section{Funding}

This work was supported by the Slovak Research and Development Agency [project no. APVV-15-0404].

\section{Acknowledgements}

I would like to thank Marcel Martončik for his contribution in forming the theoretical framework of the model and his feedback on the drafts of this paper.

The paper has been adapted from Matúš Adamkovič`s dissertation thesis. The full thesis can be found at:

https://opac.crzp.sk/?fn=detailBiblioForm\&sid=F8FE310152E9D1F1EA154E41F7FB or https://osf.io/sk4yj/.

\section{References}

Adamkovič, M. (2019). Objective poverty and willingness to delay gratification: Do different poverty thresholds and cognitive load matter? Československá psychologie, 63(Supplement 1), 2-14.

Adamkovič, M., \& Martončik, M. (2017). A Review of Consequences of Poverty on Economic Decision-Making: A Hypothesized Model of a Cognitive Mechanism. Frontiers in Psychology, 8. doi: 10.3389/fpsyg.2017.01784

Adamkovič, M., Martončik, M., \& Ropovik, I. (Preprint, 2018). The effect of economic situation on time and risk preferences: Does financial literacy matter? doi:10.31234/osf.io/5vaud

Adler, N., \& Stewart, J. (2007). The MacArthur Scale of Subjective Social Status. Dostupné na: http:/www.macses.ucsf.edu 
Ballard, I. C., Kim, B., Liatsis, A., Aydogan, G., Cohen, J. D., \& McClure, S. M. (2017). More Is Meaningful: The Magnitude Effect in Intertemporal Choice Depends on Self-Control. Psychological Science, 28(10), 1443-1454. doi:10.1177/0956797617711455

Bickel, W. K., Wilson, A. G., Chen, C., Koffarnus, M. N., \& Franck, C. T. (2016). Stuck in Time: Negative Income Shock Constricts the Temporal Window of Valuation Spanning the Future and the Past. PLOS ONE, 11(9), e0163051. doi:10.1371/journal.pone.0163051

Brown, J. R., Ivković, Z., \& Weisbenner, S. (2015). Empirical determinants of intertemporal choice. Journal of Financial Economics, 116(3), 473-486. doi:10.1016/j.jfineco.2015.04.004

Camerer, C. F., Dreber, A., Holzmeister, F., Ho, T.-H., Huber, J., Johannesson, M., ... Wu, H. (2018). Evaluating the replicability of social science experiments in Nature and Science between 2010 and 2015. Nature Human Behaviour, 2(9), 637-644. doi:10.1038/s41562-018-0399-z

Carter, E. C., Schönbrodt, F. D., Gervais, W. M., \& Hilgard, J. (2017). Correcting for bias in psychology: A comparison of meta-analytic methods. doi:10.31234/osf.io/9h3nu

Cohen, S., Kamarck, T., \& Mermelstein, R. (1983). A Global Measure of Perceived Stress. Journal of Health and Social Behavior, 24(4), 385. doi:10.2307/2136404

Curran, P. G. (2016). Methods for the detection of carelessly invalid responses in survey data. Journal of Experimental Social Psychology, 66, 4-19. doi:10.1016/j.jesp.2015.07.006

Dang, J. (2018). Can the ego be depleted? Attempts to replicate ego depletion effect and integrate its explanations (Dissertation). Available at: https://portal.research.lu.se/portal/files/35809239/242965_1_G5_Junhua_D_1_70.p df

Falk, A., Becker, A., Dohmen, T. J., Enke, B., Huffman, D., \& Sunde, U. (2015). The Nature and Predictive Power of Preferences: Global Evidence. SSRN Electronic Journal. doi:10.2139/ssrn.2691910

Falk, A., Becker, A., Dohmen, T. J., Huffman, D., \& Sunde, U. (2016). The Preference Survey Module: A Validated Instrument for Measuring Risk, Time, and Social Preferences. SSRN Electronic Journal. doi:10.2139/ssrn.2725874

Fanelli, D. (2012). Negative results are disappearing from most disciplines and countries. Scientometrics, 90(3), 891-904. doi:10.1007/s11192-011-0494-7

Fernandes, D., Lynch, J. G., \& Netemeyer, R. G. (2014). Financial Literacy, Financial Education, and Downstream Financial Behaviors. Management Science, 60(8), 1861- 1883. doi:10.1287/mnsc.2013.1849

Frederick, S. (2005). Cognitive Reflection and Decision Making. Journal of Economic Perspectives, 19(4), 25-42. doi:10.1257/089533005775196732

Frey, R., Pedroni, A., Mata, R., Rieskamp, J., \& Hertwig, R. (2017). Risk preference shares the psychometric structure of major psychological traits. Science Advances, 3, e1701381. doi:10.1126/sciadv.1701381

Gathergood, J. (2012). Self-control, financial literacy and consumer over-indebtedness. Journal of Economic Psychology, 33(3), 590-602. doi:10.1016/j.joep.2011.11.006 
Giatti, L., Camelo, L. do V., Rodrigues, J. F. de C., \& Barreto, S. M. (2012). Reliability of the MacArthur scale of subjective social status - Brazilian Longitudinal Study of Adult Health (ELSA-Brasil). BMC Public Health, 12(1). doi:10.1186/1471-245812-1096

Gonzalez, C. (2013). The boundaries of instance-based learning theory for explaining decisions from experience. Decision Making - Neural and Behavioural Approaches, 73-98. doi:10.1016/b978-0-444-62604-2.00005-8

Gonzalez, C., Lerch, J. F., \& Lebiere, C. (2003). Instance-based learning in dynamic decision making. Cognitive Science, 27(4), 591-635. doi:10.1207/s15516709cog2704_2

Greenland, S. (2003). Quantifying Biases in Causal Models: Classical Confounding vs Collider-Stratification Bias. Epidemiology, 14(3), 300-306.

doi:10.1097/01.ede.0000042804.12056.6c

Griskevicius, V., Tybur, J. M., Delton, A. W., \& Robertson, T. E. (2011). The influence of mortality and socioeconomic status on risk and delayed rewards: A life history theory approach. Journal of Personality and Social Psychology, 100(6), 10151026. doi:10.1037/a0022403

Grohmann, A. (2018). Financial literacy and financial behavior: Evidence from the emerging Asian middle class. Pacific-Basin Finance Journal, 48, 129-143.

doi:10.1016/j.pacfin.2018.01.007

Hagenaars, A. J. M., De Vos, K. \& Zaidi, A. (1994). Poverty statistics in the late 1980s: Research based on micro-data. Luxembourg: Office for official publications of the European Union.

Haushofer, J., \& Fehr, E. (2014). On the psychology of poverty. Science, 344(6186), 862867. doi:10.1126/science.1232491

Hayduk, L. A., \& Littvay, L. (2012). Should researchers use single indicators, best indicators, or multiple indicators in structural equation models? BMC Medical Research Methodology, 12(1). doi:10.1186/1471-2288-12-159

Hüffmeier, J., Mazei, J., \& Schultze, T. (2016). Reconceptualizing replication as a sequence of different studies: A replication typology. Journal of Experimental Social Psychology, 66, 81-92. doi:10.1016/j.jesp.2015.09.009

Chuang, Y., \& Schechter, L. (2015). Stability of experimental and survey measures of risk, time, and social preferences: A review and some new results. Journal of Development Economics, 117, 151-170. doi:10.1016/j.jdeveco.2015.07.008

Inzlicht, M., \& Schmeichel, B. J. (2012). What Is Ego Depletion? Toward a Mechanistic Revision of the Resource Model of Self-Control. Perspectives on Psychological Science, 7(5), 450-463. doi:10.1177/1745691612454134

Jeffreys, H. (1961). Theory of probability ( $3^{\text {rd }}$ Ed.). Oxford, UK: Oxford University Press.

Kaplan, B. A., Amlung, M., Reed, D. D., Jarmolowicz, D. P., McKerchar, T. L., \& Lemley, S. M. (2016). Automating Scoring of Delay Discounting for the 21- and 27-Item Monetary Choice Questionnaires. The Behavior Analyst, 39(2), 293-304. doi:10.1007/s40614-016-0070-9

Kim, H. B., Choi, S., Kim, B., \& Pop-Eleches, C. (2018). The role of education interventions in improving economic rationality. Science, 362(6410), 83-86.

doi:10.1126/science.aar6987 
Kirby, K. N., Petry, N. M., \& Bickel, W. K. (1999). Heroin addicts have higher discount rates for delayed rewards than non-drug-using controls. Journal of Experimental Psychology: General, 128(1), 78-87. doi:10.1037/0096-3445.128.1.78

Kline, R. B. (2016). Principles and practice of structural equation modeling ( $4^{\text {th }}$ ed.). New York: Guilford Press

Kraay, A., \& McKenzie, D. (2014). Do Poverty Traps Exist? Assessing the Evidence. Journal of Economic Perspectives, 28(3), 127-148. doi:10.1257/jep.28.3.127

Lee, M. D., \& Wagenmakers, E.-J. (2013). Bayesian cognitive modeling: A practical course. New York, NY, US: Cambridge University Press. doi: 10.1017/CBO9781139087759

Lusardi, A. (2008). Financial Literacy: An Essential Tool for Informed Consumer Choice? SSRN Electronic Journal. doi:10.2139/ssrn.1336389

Lusardi, A., Michaud, P.-C., \& Mitchell, O. S. (2017). Optimal Financial Knowledge and Wealth Inequality. Journal of Political Economy, 125(2), 431-477. doi: $10.1086 / 690950$

Mani, A., Mullainathan, S., Shafir, E., \& Zhao, J. (2013). Poverty Impedes Cognitive Function. Science, 341(6149), 976-980. doi:10.1126/science.1238041

Meier, S., \& Sprenger, C. D. (2015). Temporal Stability of Time Preferences. Review of Economics and Statistics, 97(2), 273-286. doi:10.1162/rest_a_00433

Muthukrishna, M., \& Henrich, J. (2019). A problem in theory. Nature Human Behaviour, 3(3), 221-229. doi:10.1038/s41562-018-0522-1

Nęcka, E., Gruszka, A., Orzechowski, J., Nowak, M., \& Wójcik, N. (2018). The (In)significance of Executive Functions for the Trait of Self-Control: A Psychometric Study. Frontiers in Psychology, 9. doi:10.3389/fpsyg.2018.01139

Nelson, L. D., Simmons, J., \& Simonsohn, U. (2018). Psychology's Renaissance. Annual Review of Psychology, 69(1), 511-534. doi: 10.1146/annurev-psych-122216-011836

Odum, A. L. (2011). Delay discounting: Trait variable? Behavioural Processes, 87(1), 1-9. doi:10.1016/j.beproc.2011.02.007

OECD. (2018a). Income inequality (indicator). doi: 10.1787/459aa7f1-en

OECD. (2018b). Poverty rate (indicator). doi: 10.1787/0fe1315d-en

Oldrati, V., Patricelli, J., Colombo, B., \& Antonietti, A. (2016). The role of dorsolateral prefrontal cortex in inhibition mechanism: A study on cognitive reflection test and similar tasks through neuromodulation. Neuropsychologia, 91, 499-508. doi:10.1016/j.neuropsychologia.2016.09.010

Open Science Collaboration. (2015). Estimating the reproducibility of psychological science. Science, 349(6251), aac4716-aac4716. doi:10.1126/science.aac4716

Pearl, J. (2009). Causality: Models, reasoning, and inference ( $2^{\text {nd }}$ ed.). Cambridge, England: Cambridge University Press.

Pedhazur, E. J., \& Schmelkin, L. P. (1991). Measurement, design, and analysis: An integrated approach. Hillsdale, NJ, US: Lawrence Erlbaum Associates, Inc.

Pedroni, A., Frey, R., Bruhin, A., Dutilh, G., Hertwig, R., \& Rieskamp, J. (2017). The risk elicitation puzzle. Nature Human Behaviour, 1(11), 803-809. doi:10.1038/s41562017-0219-x

Pepper, G. V., \& Nettle, D. (2017). The behavioural constellation of deprivation: Causes and consequences. Behavioral and Brain Sciences, 40. doi:10.1017/s0140525x1600234x 
Rohrer, J. M. (2018). Thinking Clearly About Correlations and Causation: Graphical Causal Models for Observational Data. Advances in Methods and Practices in Psychological Science, 1(1), 27-42. doi:10.1177/2515245917745629

Ropovik, I. (2015). A cautionary note on testing latent variable models. Frontiers in Psychology, 6. doi:10.3389/fpsyg.2015.01715

Rosseel, Y. (2012). lavaan: An R Package for Structural Equation Modeling. Journal of Statistical Software, 48(2). doi:10.18637/jss.v048.i02

Shields, G. S., Sazma, M. A., \& Yonelinas, A. P. (2016). The effects of acute stress on core executive functions: A meta-analysis and comparison with cortisol. Neuroscience \& Biobehavioral Reviews, 68, 651-668. doi:10.1016/j.neubiorev.2016.06.038

Schildberg-Hörisch, H. (2018). Are Risk Preferences Stable? The Journal of Economic Perspectives, 32(2), 135-154. doi: 10.2307/26409428

Simmons, J. P., Nelson, L. D., \& Simonsohn, U. (2011). False-Positive Psychology. Psychological Science, 22(11), 1359-1366. doi:10.1177/0956797611417632

Singh, R. K., \& Göritz, A. S. (2018). Ego Depletion Does Not Interfere With Working Memory Performance. Frontiers in Psychology, 9. doi:10.3389/fpsyg.2018.00538

Smeeding, T. (2015). Poverty, Sociology of. International Encyclopedia of the Social \& Behavioral Sciences, 753-759. doi:10.1016/b978-0-08-097086-8.32113-4

Spears, D. (2011). Economic Decision-Making in Poverty Depletes Behavioral Control. The B.E. Journal of Economic Analysis \& Policy, 11(1). doi:10.2202/1935-1682.2973

Stevens, J. (1996). Applied multivariate statistics for the social sciences (3rd ed.). Mahwah, NJ: Lawrence Erlbaum Associates.

Tangney, J. P., Baumeister, R. F., \& Boone, A. L. (2004). High Self-Control Predicts Good Adjustment, Less Pathology, Better Grades, and Interpersonal Success. Journal of Personality, 72(2), 271-324. doi:10.1111/j.0022-3506.2004.00263.x

Tourangeau, R., \& Yan, T. (2007). Sensitive questions in surveys. Psychological Bulletin, 133(5), 859-883. doi:10.1037/0033-2909.133.5.859

van Buuren, S., \& Groothuis-Oudshoorn, K. (2011). mice: Multivariate Imputation by Chained Equations inR. Journal of Statistical Software, 45(3). doi:10.18637/jss.v045.i03

Watson, D., Clark, L. A., \& Tellegen, A. (1988). Development and validation of brief measures of positive and negative affect: The PANAS scale. Journal of Personality and Social Psychology, 54, 1063-1070.

Wicherts, J. M., Veldkamp, C. L. S., Augusteijn, H. E. M., Bakker, M., van Aert, R. C. M., \& van Assen, M. A. L. M. (2016). Degrees of Freedom in Planning, Running, Analyzing, and Reporting Psychological Studies: A Checklist to Avoid p-Hacking. Frontiers in Psychology, 7. doi:10.3389/fpsyg.2016.01832

Xu, S., Pan, Y., Wang, Y., Spaeth, A. M., Qu, Z., \& Rao, H. (2016). Real and hypothetical monetary rewards modulate risk taking in the brain. Scientific Reports, 6(1). doi:10.1038/srep29520

Zimbardo, P., Clements, N., \& Rego Leite, U. (2017). Time Perspective and Financial Health: To Improve Financial Health, Traditional Financial Literacy Skills Are Not Sufficient. Understanding Your Time Perspective Is Critical. Time Perspective, 940. doi:10.1057/978-1-137-60191-9_2 

Figure 1

Conceptual visualization of the hypothesized cognitive mechanism of poverty perpetuation

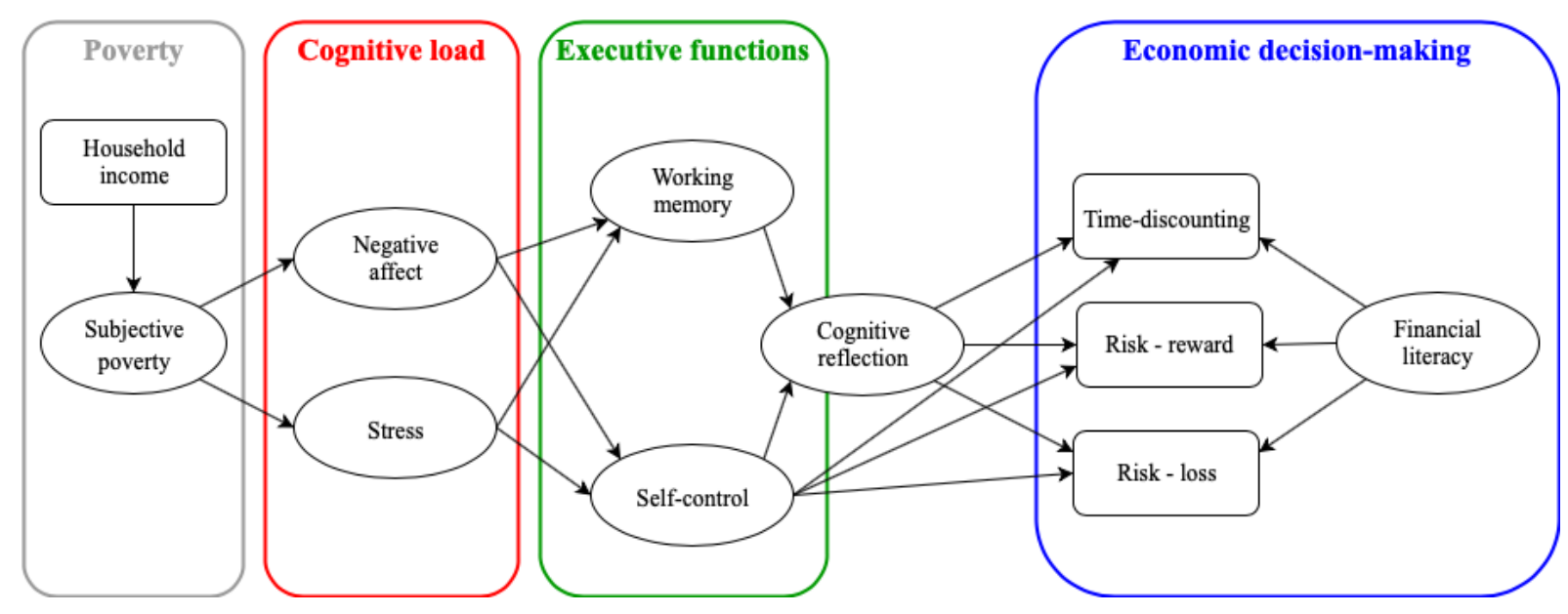

Table 1

Descriptive statistics

\begin{tabular}{lllllllllll}
\hline & \multicolumn{3}{c}{ Study 1 } & \multicolumn{3}{c}{ Study 2 } & \multicolumn{3}{c}{ Study 3 } \\
& \multicolumn{1}{c}{ M } & \multicolumn{1}{c}{ SD } & $\omega$ & \multicolumn{1}{c}{ M } & \multicolumn{1}{c}{ SD } & $\omega$ & M & SD & $\omega$ \\
\hline Income & 561 & 295 & - & 606 & 328 & - & 644 & 369 & - \\
SES & 5.30 & 1.69 & - & 4.75 & 1.60 & - & - & - & - \\
ECO & 2.92 & 0.78 & .92 & 2.87 & 0.79 & .93 & 4.66 & 1.72 & .79 \\
Wealth & 4.64 & 1.41 & - & 4.66 & 1.45 & - & - & - & - \\
NEG & 2.71 & 0.66 & .90 & 2.59 & 0.68 & .90 & - & - & - \\
Stress & 1.83 & 0.54 & .84 & 2.18 & 0.58 & .86 & 2.49 & 0.65 & .81 \\
WM & 8.75 & 1.57 & .81 & 5.70 & 2.7 & .86 & 3.35 & 1.85 & .83 \\
SC & 3.31 & 0.55 & .81 & 3.33 & 0.52 & .79 & 3.41 & 0.56 & .75 \\
CR & 2.47 & 1.78 & .87 & 2.55 & 1.79 & .88 & 2.10 & 1.41 & .80 \\
TD 1 & 18.23 & 10.70 & - & 17.45 & 10.91 & - & 11.22 & 7.77 & - \\
TD 2 & - & - & - & 0.03 & 0.06 & - & - & - & - \\
TD 3 & - & - & - & - & - & - & 2.42 & 1.45 & - \\
Risk-R & 8.66 & 7.48 & - & 8.75 & 6.74 & - & - & - & - \\
Risk-L & 21.56 & 7.70 & - & 22.2 & 7.00 & - & - & - & - \\
FL & 3.75 & 1.60 & .81 & 4.29 & 1.88 & .78 & 3.62 & 1.58 & .70 \\
\hline
\end{tabular}

Note: Income = equivalized household income; SES = subjective perception of SES; ECO = financial satisfaction scale; Wealth = perception of own poverty/wealth; NEG = negative affect; Stress $=$ perceived stress; $\mathrm{WM}=$ working memory; $\mathrm{SC}=$ self-control; $\mathrm{CR}=$ cognitive reflection; TD 1 = staircase model of time-discounting; TD 2 = IMCQ measure of timediscounting; TD 3 = time-discounting with a real monetary reward (ordered categorical); Risk-R $=$ staircase model of risk preference when a reward is involved; Risk- $\mathrm{L}=$ staircase model of risk preference when a loss is involved; FL = financial literacy 
Table 2

Model fit parameters of the tested models for all 3 studies

\begin{tabular}{lccccccc}
\hline Model & $\chi^{2}$ & $\mathrm{df}$ & $\mathrm{p}$ & $\mathrm{CFI}$ & $\mathrm{TLI}$ & RMSEA [95\% CI] & SRMR \\
\hline Study 1 & & & & & & & \\
Initial & 839.76 & 78 & $<.001$ & .76 & .82 & $.15[.15, .16]$ & .11 \\
W/ cov. & 422.02 & 80 & $<.001$ & .90 & .92 & $.10[.10, .11]$ & .09 \\
W/o FL & 188.78 & 74 & $<.001$ & .97 & .98 & $.06[.05, .09]$ & .05 \\
Study 2 & & & & & & & \\
Initial & 1024.33 & 83 & $<.001$ & .77 & .81 & $.15[.15, .16]$ & .11 \\
W/ cov. & 546.62 & 83 & $<.001$ & .89 & .91 & $.11[.10, .11]$ & .09 \\
W/o FL & 311.47 & 73 & $<.001$ & .94 & .96 & $.08[.08, .09]$ & .06 \\
Study 3 & & & & & & & $.10[.09, .11]$ \\
Initial & 231.52 & 67.20 & $<.001$ & .76 & .78 & .10 \\
W/o FL & 171.89 & 54.86 & $<.001$ & .81 & .83 & $.09[.08, .11]$ & .09 \\
\hline
\end{tabular}

Note: Initial $=$ the initial conceptualization of the model; $\mathrm{W} / \operatorname{cov}=$ the model with a covariance term between negative affect and stress; W/o FL $=$ the model without financial literacy

Table 3

Regression estimates for all 3 studies

\begin{tabular}{ccccccc}
\hline Estimates & $\mathrm{b}$ & $\mathrm{SE}$ & $\mathrm{p}$ & $\beta$ & $\mathrm{BF}_{10}$ & Posterior \\
\hline SES $\sim$ & & & & & & \\
Income & 0.17 & 0.02 & $<.001$ & 0.45 & $5 \mathrm{e} 16$ & 1 \\
& $\mathbf{0 . 2 2}$ & $\mathbf{0 . 0 2}$ & $<.001$ & $\mathbf{0 . 5 9}$ & $\mathbf{7 e 3 0}$ & $\mathbf{1}$ \\
& 0.17 & 0.03 & $<.001$ & 0.52 & $5 e 12$ & 1 \\
NEG $\sim$ & & & & & & \\
SES & -0.30 & 0.05 & $<.001$ & -0.32 & $1 \mathrm{e} 05$ & 1 \\
& $\mathbf{- 0 . 2 6}$ & $\mathbf{0 . 0 4}$ & $<.001$ & $\mathbf{- 0 . 3 0}$ & $\mathbf{9 e 0 6}$ & $\mathbf{1}$ \\
Stress $\sim$ & & & & & & \\
SES & -0.35 & 0.05 & $<.001$ & -0.37 & $3 \mathrm{e} 05$ & 1 \\
& $\mathbf{- 0 . 2 8}$ & $\mathbf{0 . 0 5}$ & $<.001$ & $\mathbf{- 0 . 3 2}$ & $\mathbf{1 e 0 7}$ & $\mathbf{1}$ \\
WM $\sim$ & -0.22 & 0.08 & .008 & -0.25 & 20.8 & .95 \\
NEG & 0.12 & 0.23 & .597 & 0.12 & 0.06 & .05 \\
& $\mathbf{0 . 1 6}$ & $\mathbf{0 . 1 8}$ & $\mathbf{. 3 7 7}$ & $\mathbf{0 . 1 6}$ & $\mathbf{0 . 0 5}$ & $\mathbf{. 0 4}$ \\
Stress & -0.38 & 0.23 & .096 & -0.39 & 0.05 & .05 \\
& $\mathbf{- 0 . 3 1}$ & $\mathbf{0 . 1 7}$ & $\mathbf{. 0 7 3}$ & $\mathbf{- 0 . 3 2}$ & $\mathbf{0 . 0 7}$ & $\mathbf{. 0 7}$ \\
& -0.15 & 0.09 & .189 & -0.12 & 0.08 & .07 \\
SC $\sim$ & & & & & & \\
NEG & -0.44 & 0.15 & .003 & -0.41 & 1.22 & .55 \\
Stress & $\mathbf{- 0 . 3 1}$ & $\mathbf{0 . 1 6}$ & $\mathbf{. 0 6 0}$ & $\mathbf{- 0 . 2 8}$ & $\mathbf{0 . 4 3}$ & $\mathbf{. 3 0}$ \\
& -0.05 & 0.15 & .746 & -0.05 & 0.05 & .05 \\
& $\mathbf{- 0 . 2 6}$ & $\mathbf{0 . 1 6}$ & $\mathbf{. 1 1 3}$ & $\mathbf{- 0 . 2 4}$ & $\mathbf{0 . 0 5}$ & $\mathbf{. 0 5}$ \\
& -0.58 & 0.10 & $<.001$ & -0.51 & $4 e 4$ & 1
\end{tabular}




\begin{tabular}{|c|c|c|c|c|c|c|}
\hline \multicolumn{7}{|l|}{$\mathrm{CR} \sim$} \\
\hline \multirow[t]{3}{*}{ WM } & 0.60 & 0.13 & $<.001$ & 0.53 & $1 \mathrm{e} 04$ & 1 \\
\hline & 0.19 & 0.06 & .002 & 0.18 & 2.40 & .71 \\
\hline & 0.05 & 0.10 & .637 & 0.05 & 0.07 & .06 \\
\hline \multirow[t]{3}{*}{$\mathrm{SC}$} & -0.15 & 0.07 & .024 & -0.15 & 3.75 & .79 \\
\hline & 0.10 & 0.06 & .060 & 0.12 & 0.12 & .10 \\
\hline & -0.08 & 0.09 & .418 & -0.09 & 0.28 & .22 \\
\hline \multicolumn{7}{|l|}{ TD $1 \sim$} \\
\hline \multirow[t]{3}{*}{$\mathrm{CR}$} & 0.15 & 0.05 & .003 & 0.18 & 0.06 & .06 \\
\hline & 0.12 & 0.05 & .016 & 0.13 & 0.31 & .24 \\
\hline & 0.42 & 0.63 & .510 & 0.06 & 0.21 & .17 \\
\hline \multirow[t]{3}{*}{$\mathrm{SC}$} & -0.02 & 0.05 & .633 & -0.03 & 0.10 & .09 \\
\hline & 0.02 & 0.05 & .727 & 0.02 & 0.05 & .05 \\
\hline & 0.15 & 0.45 & .736 & 0.02 & 0.06 & .06 \\
\hline \multirow[t]{3}{*}{ FL } & 0.27 & 0.06 & $<.001$ & 0.27 & 500 & 1 \\
\hline & 0.18 & 0.05 & .001 & 0.18 & 3.31 & .77 \\
\hline & 0.24 & 0.62 & .697 & 0.03 & 0.07 & .07 \\
\hline \multicolumn{7}{|c|}{ Risk-R } \\
\hline \multirow[t]{2}{*}{$\mathrm{CR}$} & 0.04 & 0.05 & .377 & 0.05 & 0.07 & .07 \\
\hline & 0.07 & 0.05 & .141 & 0.07 & 0.15 & .13 \\
\hline \multirow[t]{2}{*}{$\mathrm{SC}$} & 0.05 & 0.05 & .329 & 0.05 & 0.07 & .06 \\
\hline & -0.03 & 0.05 & .473 & -0.04 & 0.14 & .12 \\
\hline \multirow[t]{2}{*}{ FL } & 0.14 & 0.05 & .010 & 0.14 & 1.89 & .65 \\
\hline & 0.04 & 0.05 & .440 & 0.04 & 0.05 & .04 \\
\hline \multicolumn{7}{|c|}{ Risk-L } \\
\hline \multirow[t]{2}{*}{$\mathrm{CR}$} & -0.14 & 0.04 & .001 & -0.17 & 0.24 & .19 \\
\hline & 0.01 & 0.05 & .845 & 0.01 & 0.05 & .05 \\
\hline \multirow[t]{2}{*}{$\mathrm{SC}$} & 0.00 & 0.05 & .959 & 0.00 & 0.05 & .05 \\
\hline & -0.08 & 0.04 & .071 & -0.09 & 0.05 & .05 \\
\hline \multirow[t]{2}{*}{ FL } & -0.10 & 0.05 & .042 & -0.10 & 0.05 & .05 \\
\hline & -0.10 & 0.05 & .027 & -0.10 & 0.23 & .19 \\
\hline \multicolumn{7}{|l|}{ TD $2 \sim$} \\
\hline CR & -0.20 & 0.04 & $<.001$ & -0.21 & 0.21 & .17 \\
\hline $\mathrm{SC}$ & 0.05 & 0.04 & .266 & 0.06 & 0.37 & .27 \\
\hline FL & -0.22 & 0.05 & $<.001$ & -0.22 & 4.11 & .80 \\
\hline \multicolumn{7}{|l|}{ TD $3 \sim$} \\
\hline CR & 0.06 & 0.12 & .607 & 0.04 & 0.07 & .07 \\
\hline $\mathrm{SC}$ & -0.09 & 0.10 & .364 & -0.07 & 0.08 & .08 \\
\hline FL & 0.49 & 0.12 & $<.001$ & 0.34 & 84.3 & .99 \\
\hline
\end{tabular}

Note: Estimates from Study 1 are written in regular font, estimates from Study 2 are in bold, estimates from Study 3 are in italic. Income = equivalized household income; SES $=$ subjective perception of own socioeconomic situation (only the financial satisfaction scale in Study 3); NEG = negative affect; Stress = perceived stress; $\mathrm{WM}=$ working memory; $\mathrm{SC}=$ self-control; $\mathrm{CR}=$ cognitive reflection; $\mathrm{TD} 1=$ staircase model of timediscounting; TD 2 = IMCQ measure of time-discounting; TD 3 = time-discounting with a real monetary reward (ordered categorical); Risk-R = staircase model of risk preference when a reward is involved; Risk- $\mathrm{L}=$ staircase model of risk preference when a loss is involved; $\mathrm{FL}=$ financial literacy 